\title{
O TEXTO SE LIMITA? DISCUSSÃO BASEADA EM GÉRARD GENETTE E JOÃO DO RIO
}

Tiago de Holanda Padilha Vieira*

\author{
tiagovieira@ufmg.br \\ Mestrando em Estudos Literários pela UFMG.
}

RESUMO: O conceito de "paratexto" apresentado por Gérard Genette pressupõe que o texto literário delimita um território inequívoco e, idealmente, inviolável. Essa concepção de texto é análoga à noção de livro enquanto "fortaleza", enquanto totalidade autossuficiente cujos significados estariam contidos em si mesma, como descreve Michel Melot. Porém, os elementos que Genette define como "paratextos" tambem podem se prestar a deslimitação do texto e, pois, do livro, contribuindo para lançá-lo para "fora" de si mesmo, ou melhor, para questionar o pressuposto de que haja "dentro" e "fora", A partir da análise de dois posto de que haja "d tro" e "fora". A parir da análise de dois nista João do Rio, pretendes refletir sobre como pode ocorrer nista Joăo do Rio, pretendemos refletir sobre como pode ocorrer essa indeterminação de demarcações, ainda que haja sempre índices determinantes em qualquer contexto de leitura.

PALAVRAS-CHAVE: paratexto e texto; livro; $A$ alma encantadora das ruas.
ABSTRACT: The concept of "paratext" defined by Gérard Genette assumes that the literary text delimits an unambiguous, ideally inviolable territory. This conception of text is analogous to the notion of book as "fortress", as a self-sufficient totality that is thought to contain its own meanings, according to the description presented by Miche Melot. However, the elements defined by Genette as "paratexts" might contribute to disrupt the supposed limits of the text and, therefore, of the book, in concurring to throw it "outside" itself, or rather, to challenge the assumption that it has an "inside" and an "outside". Building on an analysis of (the tho ruas, by the cronista Joano do Rio, we aim to discuss the ways in which such indetermination of limits might occur, although there
are always determining indications in any context of reading.

KEYWORDS: paratext and text; book; $A$ alma encantadora das ruas. 
1. GENETTE. Paratextos editoriais, p. 9.

2. GENETTE. Paratextos editoriais, p. 10.
O teórico Gérard Genette apresenta, em seu livro Paratextos Editoriais, o conceito de paratexto da obra literária. Segundo ele, tal conceito compreende produções, verbais ou não, que acompanham um texto literário. O paratexto cerca e prolonga o texto, "exatamente para apresentá-lo, no sentido habitual do verbo, mas também em seu sentido mais forte: para torná-lo presente, para garantir sua presença no mundo, sua 'recepção' e seu consumo"1. Como exemplos de paratexto, podem-se citar de um texto o nome do autor, o título, o prefácio e mesmo "mensagens" situadas fora do livro (por exemplo, carta do autor ou entrevistas jornalísticas referentes à sua obra).

O termo "acompanhamento" é importante para entender-se a definição proposta por Genette. Embora este considere que o paratexto constitui uma "zona indecisa" entre o dentro e o for do texto ${ }^{2}$ - embora sugira, sem percorrê-los, alguns caminhos pelos quais o "espaço" do paratexto pode ser questionado até ao ponto de ser deslimitado -, prevalece a ideia de que o texto é acompanhado por algo que não se deve confundir com o texto. Parece vigorar uma separação fundamentada em materialidades distintas. O texto seria um "território" verbal que, apesar de sofrer de algum modo a ação do paratexto, é (e deve ser mantido) inteiriço, sem correr o risco de perder e, sobretudo, de ganhar itens "materiais" estranhos a seu acervo "legítimo".

Considero essa separação, relativamente e em certo sentido, pouco relevante, nos mesmos termos nos quais Michel
Foucault enuncia tal apoucada relevância: "a unidade material do volume não será uma unidade fraca, acessória, em relação à unidade discursiva a que ela dá apoio? Mas essa unidade discursiva, por sua vez, será homogênea e uniformemente aplicável?”’3. Se se levar em conta que o paratexto participa da "ativação" do "território" verbal do texto, como o próprio Genette permite entender em alguns trechos de seu referido livro, então paratexto e texto são indiscerníveis na operação de leitura, considerada esta enquanto processo de significação. A leitura pode se iniciar antes mesmo de o livro enquanto objeto físico ser disponibilizado ao público ${ }^{4}$. O leitor pode começar a "lê-lo" antes de pôr mãos e olhos na "matéria-livro". O paratexto, portanto, participa do "consumo" do texto, sem que essa participação seja inteiramente descritível ou previsível. Pode-se imaginar a hipótese de, no contexto de leitura de um texto, uma ínfima nota de rodapé editorial ter efeito mais significativo sobre um leitor do que qualquer dos outros paratextos aos quais este tenha acesso.

Nossas considerações sobre o paratexto - apesar de ter-se problematizado o conceito proposto por Genette, continuaremos a empregar o termo que ele afirma ter "batizado" - permitem notar que essa categoria, por definição, contraria a ideia de texto enquanto unidade, ou totalidade, autossuficiente. No entanto, elementos paratextuais podem ser empregados de modo a tentar-se corroborar o que Michel
3. FOUCAULT. A arqueologia do saber, p. 25-26.

4. Pode-se dizer, em sentido muito amplo, que a leitura de um livro se inicia sempre antes de se publicálo, se se pensa que o livro se insere em uma rede textual e cultural ilimitada, e que a leitura dele "propriamente dita" é antecedida e atravessada por essa rede. Como aponta Foucault: "É que as margens de um livro jamais são nítidas nem rigorosamente determinadas: alem do título, das primeiras linhas e do ponto final, além de sua configuração interna e da forma que lhe dá autonomia, ele está preso em um sistema de remissões a outros livros, outros textos, outras frases: nó em uma rede" (FOUCAULT. A arqueologia do saber, p. 26).
EM TESE
BELO HORIZONTE
v. 22
N. 3
SET.-DEZ. 2016
VIEIRA. 0 texto se limita? Discussão baseada em Gérard Genette e [...]
P. $171-182$ 
Melot chama de "concepção unitária do livro"s. O objetivo do presente trabalho é discutir de que maneiras - em outras palavras, por meio de quais efeitos de leitura - o paratexto pode (re)afirmar e, ao mesmo tempo, recusar tal noção de livro. Essa questão básica, de clara relevância para a crítica literária, será pensada por meio da análise de dois itens paratextuais de $A$ alma encantadora das ruas (daqui em diante, o título se abreviará como $A$ alma), coletânea de textos de João do Rio. Os itens a serem examinados são a epígrafe e um dos textos, o qual, julgamos, exerce um papel dúbio ao integrar-se ao "território" da coletânea e ao "destacar-se" desta para prefaciá-la.

Antes de passar-se ao estudo da antologia, cabe explicar a noção unitária de livro a ser discutida. Segundo Melot, o livro não é apenas a embalagem de um conteúdo. A dobra dele possui uma forma, não restrita esta à sua "geometria perfeita" ${ }^{\prime}$, mas denotando um modo de funcionamento, uma engrenagem. "A forma do livro pensa antes de ser escrita" . O livro se apresenta como fechado sobre si mesmo, como mônada, existência autônoma e completa, perfeitamente acabada. O livro, pressupõe-se, deve ter um sentido, de modo a "dissimular diversidades, até mesmo incoerências inaceitáveis para seu estado". A forma-livro sugere - ou exclama, autoritariamente - que, na leitura de um livro, eventuais desagregações ou indeterminações são apenas dificuldades temporárias, provocadas, provavelmente, pela imperícia do leitor. As aparentes lacunas fatalmente se preencheriam - ou melhor, se revelariam cheias desde o princípio -, pois o livro e o que ele carrega teriam sido planejados de modo a que se compusesse um corpo irretocavelmente orgânico. "Todo livro é um projeto. Ele sabe aonde ir, mesmo quando se torna patente que ele não irá a lugar nenhum".

A caracterização apresentada por Melot para a forma-livro soa demasiado rígida. É certo que o livro acomoda a regras precisas o que nele se inscreve ou imprime, mas seu conteúdo e a leitura deste ${ }^{10}$ podem estabelecer uma relação tensa com tal "pequena fortaleza"11, podem desafiar esta e talvez, ao menos em alguma medida e de forma instável, conseguir subvertê-la. Em certo sentido, a leitura sempre lança o livro para "fora" de si mesmo ${ }^{12}$, derramamento que Melot parece sugerir no seguinte excerto: "Um livro é escrito uma única vez. E toda leitura o faz renascer, sempre, de uma forma diferente"13. A perfeição pressuposta na e pela forma-livro, a premissa da leitura enquanto progressão dirigida à completude, coexiste com o fato de o livro ser refeito, repetida e interminavelmente.

Uma vez que analisaremos elementos paratextuais de uma coletânea, um trecho do livro de Melot é especialmente pertinente:
10. Apesar dessa formulação, julgase que é impossível isolar-se um conteúdo "puro" (anterior e exterior às circunstâncias de um processo de leitura), ideia explicitada ao longo do presente trabalho.

11. MELOT. Livro, p. 49

12. Dizemos "fora de si mesmo", porque consideramos que essa concepção da forma-livro pressupõe que o livro possui "dentro" e "fora", isto é, possui fronteiras demarcáveis. O presente trabalho se opõe a essa premissa.

13. MELOT. Livro, p. 54 . 
Onde o discurso foi rompido, o livro o reacomoda. Ele funciona como uma tela de fundo que se aplica nos fragmentos de afrescos que se desencaixaram para consolidá-los e os reintegrar em um espaço sólido e fechado. A forma do livro preenche os vazios dos discursos, os quais, sem ela, se desintegrariam ${ }^{14}$.

A capa do livro "fixa o provisório no permanente, transforma o diverso no único"15. Podemos dizer que a esse efeito se submete a coletânea de João do Rio, a qual reúne 25 crônicas e dois ensaios - ou, talvez, 27 crônicas. Independentemente de o leitor saber ou mesmo questionar se esses textos foram originalmente concebidos como membros de um conjunto coeso e unitário, é este o aspecto que ganham, ao menos em um primeiro momento, por estarem contidos em um mesmo livro, sob um único título.

O efeito de totalidade persiste, ainda que se pense na hipótese de o leitor saber que os textos se publicaram, inicialmente, separados entre si, em periódicos jornalísticos. O fato de aqueles terem sido coligidos em um livro sugere que fazem parte de um projeto que os considera dignos de permanecerem, de serem resgatados da fugacidade dos jornais e revistas - "um jornal é lido para o esquecimento. (...) E um livro lido para se lembrar", afirma Jorge Luis Borges, citado por Melot $^{16}$. O planejamento pressuposto na forma-livro, no caso de $A$ alma, sugere também que os textos, embora a princípio dispersos, guardariam relações mútuas que justificariam a agregação e estariam inscritas no livro, à espera de um leitor que as desvelasse.

"O tempo do livro é ritmado pela forma, pela página e por seu tamanho. (...) O tempo do livro é o tempo fragmentado, ademais, como a dobra o mensura, ele é normatizado. O tempo do livro é determinado pelo espaço" ${ }^{\prime 1}$. Segundo esse modelo, o livro prescreve uma leitura linear, que segue da origem à conclusão. Entretanto, podemos pensar em elementos do livro que sugiram que se saia da página, que se façam perquirições fora da dobra ou em outras dobras. Um livro pode sugerir interrupções que, se se leva em conta uma noção expandida de livro, não são (inteiramente) interrupções, mas sim deslocamentos espaciais, mudanças de ritmo. Pois, se alguém suspende uma leitura para assistir a um filme ao qual um livro se refere, essa atividade de espectador, em alguma medida, não é ainda a mesma leitura? Não é a "leitura" de um outro que também é a leitura de um mesmo?

As questões do parágrafo acima ensejam o começo da reflexão sobre a epígrafe de $A$ alma. A epígrafe é formada por três frases atribuídas ao escritor inglês Jerome K. Jerome. O nome deste se segue, imediatamente, à citação: “This is a sensible book. This is a book to improve your mind. I do not tell you all I know, because I do not want to swamp you with knowledge..." ${ }^{18}$. A citação pode ter diversos efeitos. Pode ser ignorada, como se 
fosse irrelevante, por quem percorre o livro. Por outro lado, se não for desprezada, pode estimular a que permaneça na "fortaleza" do livro o leitor, mas também pode incitar este a planejar e realizar um deslocamento mais ou menos extenso.

Um leitor pode julgar a epígrafe somente um comentário introdutório e breve sobre o livro de João do Rio, comentário que o cronista, por alguma razão que pode não ser questionada, achou adequado buscar na obra de outro autor. Se a epígrafe for assim considerada, é provável que o leitor se sinta estimulado a permanecer no território da "fortaleza". "This is a book" - presume-se, nessa leitura, que os termos apontem para A alma e reafirmem, portanto, a unidade do livro. Percebe-se que este é classificado como "sensible" e que seu objetivo manifesto é "to improve your mind", e deduz-se que este "your" se refere ao leitor. O autor - infere-se que João do Rio fala através da "boca" de Jerome - declara ter ocultado deliberadamente alguns dados, pois não quer "inundar", ou "encharcar", de conhecimento o leitor.

A epígrafe pode se afigurar simples, mas, de fato, é um tanto enigmática. Nesse contexto, o que pode significar ser "sensato"? A impossibilidade de alguém comunicar tudo o que sabe parece óbvia, de modo que não soa aceitável pensar que a citação ("I do not tell you all I know") pressuponha a eventualidade de alguém realizar o irrealizável. Inquietamo-nos: o livro oculta quais dados, especificamente? Caso o autor não os ocultasse, quais seriam as consequências? O que pode significar "inundar" de conhecimento alguém? A partir de tais interrogações, o leitor pode se sentir incitado a largar $A$ alma, temporariamente, e seguir (e ao mesmo tempo construir) algumas "pegadas" - é a isso que se refere o "deslocamento mais ou menos extenso" enunciado dois parágrafos acima.

Ao deslocar-se, o leitor pode descobrir que a citação é autêntica, mas inexata. As três frases que a compõem estão no prefário do livro Diary of a pilgrimage, de Jerome, publicado em 1891. Porém, originalmente, elas estão entremeadas por outras frases. O objetivo aqui não é fazer uma análise pormenorizada do prefácio de Jerome, mas vejamos como tal paratexto pode ser usado para enfrentar-se uma das questões enunciadas acima - a saber: o que pode significar "inundar" de conhecimento alguém?. A expressão "to swamp" é assim explicada pelo escritor inglês:

I should only be defeating my own object did I, by making you think too much at first, give you a perhaps, lasting dislike to the exercise. I have purposely put the matter in a light and attractive form, so that I may secure the attention of the young and the frivolous. I do not want them to notice, as they go on, that they are being instructed; and I have, therefore, endeavoured to disguise from them, so far as is practicable, that this is either an exceptionally clever or an exceptionally 
19. JEROME. 14 books in 1, p. 123.

20. Aqui, um curto comentário sobre outro paratexto: o título do livro de Jerome. "Diary of a pilgrimage" sugere aproximações significativas com o livro brasileiro. Sem no delongarmos em definições genéricas, salientamos que o que "diário denota um tex que se expressa na primeira individuais do enusciador. Já "peregrinacão" designa Ju viagem por terras distantes, por países longínquos. As narrativas de João do Rio, embora não componham um diário, centram se nas observações e sensações de um narrador-personagem que visita espaços frequentados por um estrato social do qual manifest não fazer parte: a "classe baixa" da cidade do Rio de Janeiro. 0 narrador se expõe ao desconforto de lugares apertados, abafados, escuros, sujos - cidades estranhas dentro da mesma cidade,

"países longinquos". Realiza-se uma especie fragmentária de peregrinação, cujos pedaços se reúnem em um peculiar "relato de viagem". A citação ao livro de Jerome pode inspirar tais ressonâncias. useful work. I want to do them good without their knowing it. I want to do you all good - to improve your minds and to make you think, if I can ${ }^{19}$.

Nesse trecho, o termo "you" deve se aplicar, por não especificar uma referência e por estar no plural ("your minds"), a qualquer leitor do livro. O texto é ambíguo em relação à qualidade de seu leitor - este é, necessariamente, "young and frivolous"? Seja qual for a resposta, outra questão deve ser enfrentada: como uma leitura desse excerto pode contribuir para uma interpretação da epígrafe de $A$ alma? É possível que a coletânea pressuponha a mesma relação entre texto e leitor, e que tal pressuposto seja perceptível nos textos coligidos? Em perspectiva mais geral, de que modo e em que medida o livro de Jerome pode se fazer pertinente a uma interpretação sobre o livro de João do Rio? Quais os limites, supondo que estes existam, das relações que se podem estabelecer entre as duas obras, ou melhor, das relações possivelmente incitadas pela epígrafe? ${ }^{20}$

Não se deve descartar a hipótese de que, em A alma, a menção ao nome de Jerome K. Jerome seja mais expressiva do que as frases extraídas de um de seus livros. Escreve Genette:

numa epígrafe, o essencial muitíssimas vezes não é o que ela diz, mas a identidade de seu autor e o efeito de garantia indireta que sua presença determina à margem de um texto (...). Por isso, a coisa importante num grande número de epígrafes é apenas o nome do autor citado ${ }^{21}$.

Qual a natureza e a extensão do vínculo que a epígrafe analisada estabelece entre $A$ alma e Diary of a pilgrimage? Tal vínculo pode ser expandido para aproximações entre o livro de João do Rio e outras obras de Jerome? Pode estimular uma comparação extensa entre as bibliografias dos dois autores? Pode, ainda, sugerir uma aproximação entre as maneiras como estes, em seus respectivos tempos e espaços, lidavam com o leitorado e a crítica, tendo-se em vista o tratamento ambíguo concedido por Jerome a seus leitores e a preocupação, talvez irônica, comum a ambos os autores em publicarem algo "sensato"?

Citemos outro trecho de Genette:

Tem-se observado com razão, no excesso epigráfico do início do século XIX, um desejo de integrar o romance, e em particular o romance histórico ou "filosófico", numa tradição cultural. (...) A epígrafe é por si só um sinal (que se quer indice) de cultura, uma palavra-passe para a intelectualidade. (...) ela já é um pouco a sagração do escritor, que por meio dela escolheu seus pares e, portanto, seu lugar no Panteão ${ }^{22}$.
21. GENETTE. Paratextos editoriais, p. 143.
22. GENETTE. Paratextos editoriais, p. 144. 
23. GENETTE. Paratextos editoriais, p. 141.
A epígrafe de $A$ alma integra o livro a alguma "tradição cultural" ou sugere que este se proponha a integrar alguma? A epígrafe pode se incluir em um hipotético plano de João do Rio para ser respeitado, em uma tentativa de entrar no "primeiro escalão" dos escritores de seu tempo, entrada recusada por diversos críticos (por exemplo, Gilberto Freyre em Ordem e progresso)?

As questões concernentes à epígrafe de $A$ alma remetem-nos a uma pergunta fundamental: é factível circunscrever as funções de uma epígrafe? Em outras palavras, é possíve delimitar e descrever os efeitos potenciais, em uma leitura ou sobre um leitor, de tal paratexto? Genette parece acreditar que sim, contanto que se realize uma pesquisa suficientemente ampla, embora ele reconheça que tais efeitos, sob dependência do leitor, podem ou não ser ativados: "Sem dúvida, por não ter ampliado minha pesquisa, vejo quatro funções da epígrafe, nenhuma das quais é explícita, já que epigrafar é sempre um gesto mudo cuja interpretação fica a cargo do leitor"23.

O teórico francês pressupõe, também, que a epígrafe e o livro que a inclui contêm seus próprios significados - ou um único significado -, que devem ser descobertos. Esse pressuposto se explicita, por exemplo, na afirmação de que uma função da epígrafe seria fazer um "comentário do texto, cujo significado ela precisa ou ressalta indiretamente", e de que esse comentário é "na maioria das vezes enigmático, de um significado que somente se esclarecerá, ou confirmará, com a plena leitura do texto"24. Na perspectiva de Genette - que, assim, reafirma a feição da forma-livro caracterizada por Melot -, não há nada, a princípio, que impeça que o significado seja alcançado definitivamente.

Outra premissa de Genette, supostamente válida para todo paratexto, é a de que a epígrafe não faz parte do texto - premissa baseada na já analisada concepção de texto enquanto "território" delimitado por um conjunto de inscrições ver bais. A epígrafe, assim, constituiria uma "citação colocada em exergo", sendo que, "no caso, o exergo é mais uma borda da obra, geralmente mais perto do texto" ${ }^{25}$. Consideramos pouco expressiva essa separação, como já se explicou acima. Ademais, a discussão sobre a epígrafe de $A$ alma mostra que não é possível divisar, precisa e exaustivamente, suas funções. Tampouco se pode encerrar o significado do livro, pois que a "obra" não tem sequer limites claramente identificáveis. Qualquer epígrafe, ainda que se reporte, direta ou indiretamente, ao volume no qual se inscreve, também contribui para deslimitá-lo, misturá-lo a outro(s) livro(s), sem que a leitura do outro deixe de ser, necessariamente, a leitura do mesmo. Um leitor, por exemplo, abandona temporariamente o volume identificado com o título de $A$ alma e desloca a atenção para o prefácio de Diary of a pilgrimage, a fim de ampliar as
24. GENETTE. Paratextos editoriais, p. 142.

25. GENETTE. Paratextos editoriais, p. 131.

EM TESE

BELO HORIZONTE

v. 22

N. 3

SET.-DEZ. 2016

VIEIRA. 0 texto se limita? Discussão baseada em Gérard Genette e [... .]

P. $171-182$ 

26. GENETTE. Paratextos editoriais, possibilidades de interpretação da epígrafe de João do Rio - tal deslocamento prolonga a leitura de $A$ alma, em vez de interrompê-la.

A epígrafe de $A$ alma é sucedida pelo ensaio "A rua", primeiro texto da coletânea. Esse ensaio, cuja análise iniciamos agora, exerce função prefacial, embora esta não seja declarada no livro. A classificação proposta aqui realça algumas interrogações conceituais, se se tentar examiná-la com base nos parâmetros que, na visão de Genette, definem o prefácio moderno como "toda espécie de texto liminar (preliminar ou pós-liminar), autoral ou alógrafo, que consiste num discurso produzido a propósito do texto que segue ou que antecede" ${ }^{26}$. Nessa perspectiva, "A rua" é paratexto ou faz parte do texto do livro? Ou será que, participando do texto, tem caráter paratextual? A última hipótese, porém, constitui um contrasenso, já que, para Genette, o paratexto necessariamente margeia o texto.

Pode-se, em outra direção, alegar que "A rua" seja um caso de "prefácio integrado", tal como era praticado no que Genette chama de "pré-história" do prefácio. No entanto, o presente trabalho rejeita, também, essa opção classificatória, a qual sublinha limitações teóricas de Paratextos editoriais. A ideia de que o prefácio moderno, situado em um limiar, tenha abolido uma prévia integração implica a aceitação da possibilidade de conceber-se uma zona de passagem entre o "dentro" e o "fora" do texto e, por extensão, entre um interior e um exterior da obra. O presente trabalho, como já se evidenciou, contrapõe-se a tal pressuposto, na medida em que ultrapassarmos a "matéria-livro".

Apesar dos desacordos quanto às proposições básicas de Genette, são úteis, para que se investigue "A rua”, algumas das análises que o teórico apresenta sobre funções exercidas pelo prefácio ${ }^{27}$. Dentre os diversos tipos de prefácio catalogados em Paratextos editoriais, o chamado "autoral assuntivo original” é o que mais se aproxima das características prefaciais do ensaio de $A$ alma, já que este é reconhecido como produto de João do Rio e está presente no livro desde a primeira edição. Não é pertinente, porém, atribuir ao texto "A rua" a qualidade de ser "assuntivo", termo que indica que o "autor real, em seu prefácio, reivindica ou, mais simplesmente, assume a responsabilidade do texto"28 - nesta citação, o termo "texto" exclui o paratexto. Não há, em "A rua”, qualquer referência direta à coletânea.

O prefácio autoral assuntivo original, segundo Genette, "tem por função principal garantir ao texto uma boa leitura" 29 . Tal prefácio indicaria, portanto, por que e como se deve ler o livro prefaciado. Este parece ser um objetivo de "A rua”, se se considerar que uma "boa leitura" não é, necessariamente, clara, precisa, acabada; essa expressão pode designar diversas propostas, inclusive a de estimular-se no leitor a dúvida, a
27. Consideramos mais pertinente tratar de como podem se produ determinadas funções do que perguntar quais são essas funçoes. As funçoes se exercem em relaçāo a leitores e contextos de leitura; não estão simplesmente "contidas" em um "em-si" do (para)texto, à espera de alguem capaz de traze las à luz e catalogá-las.

28. GENETTE. Paratextos editoriais, p. 164

29. GENETTE. Paratextos editoriais, p. 176. 
30. GENETTE. Paratextos editoriais, p. 186.

31. RIO. $A$ alma encantadora das ruas p. 29.

34. RIO. $A$ alma encantadora das ruas, p. 31. confusão. O ensaio de João do Rio, como veremos abaixo, gera pontos de indeterminação que problematizam a ideia de que a coletânea se conforme por uma arquitetura coesa coerente. Em outras palavras, o ensaio serve como desafio à concepção unitária de livro.

Apesar de distinguir os "temas do porquê" e os "temas do como" indicados no prefácio, Genette reconhece a possibilidade de ambos os "grupos de funções" se apresentarem como indiscerníveis entre $\mathrm{si}^{30}$. Em "A rua", os porquês e comos são inseparáveis. O parágrafo de abertura propõe o que seria um forte motivo para ler-se o livro e para este ter sido escrito: todos nós - quer dizer, o "eu" pelo qual o enunciador se refere a si mesmo e o "vós" com que se designam os leitores - amamos a rua. Em seguida, oferece-se uma definição complexa para o termo "rua", em uma tentativa de valorizar ainda mais o tema e apontar sua imensurável importância. Tal definição é muito mais ampla do que aquela habitual nos dicionários: "A rua era para eles apenas um alinhado de fachadas, por onde se anda nas povoações... Ora, a rua é mais do que isso, a rua é um fator da vida das cidades, a rua tem alma!"31.

O ensaio de João do Rio é dedicado, então, a explorar a vastidão semântica da afirmação de que a rua tem alma, operação exploratória que, indiretamente, constitui uma explicação sobre o título do livro. Observa-se que as ruas "pensam, têm ideias, filosofia e religião"; são a "causa fundamental da diversidade dos tipos urbanos"32. Por essa razão, as ruas compõem a "preocupação maior, a associada a todas as outras ideias do ser das cidades"33. Interessa-nos, especialmente, ressaltar que o espaço-rua ganha contornos vagos e porosos; não se sabe ao certo onde ele começa e termina; ele extrapola qualquer "fisicidade" ou geografia, sendo, talvez, impossível representá-lo em um mapa cartográfico. As ruas, comparadas aos humanos em mais de um trecho, ganham caracteres individuais ao longo do tempo. Misturam-se a seus "ocupantes" (edifícios, gestos, movimentos, temperamentos), sem, contudo, confundir-se com eles - mas o que, exatamente, separa as ruas do que as "ocupa"?

Em "A rua”, faz-se considerações sobre um "método" empregado, deliberadamente, não apenas para a escrita do mesmo ensaio, mas também para produzirem-se as crônicas subsequentes. Chamamos de método - também podemos chamar de perspectiva - a flânerie que o enunciador afirma ter praticado com o intento de conhecer as ruas e recolher histórias.

Para compreender a psicologia da rua não basta gozar-lhe as delícias como se goza o calor do sol e o lirismo do luar. É preciso ter espírito vagabundo, cheio de curiosidades malsãs e os nervos com um perpétuo desejo incompreensível, é preciso ser aquele que chamamos flâneur e praticar o mais interessante dos esportes $-\mathrm{a}$ arte de flanar ${ }^{34}$.
32. RIO. $A$ alma encantadora das ruas, p. $38-40$.

33. RIO. $A$ alma encantadora das ruas, p. 44.
EM TESE
BELO HORIZONTE
v. 22
N. 3
SET.-DEZ. 2016
VIEIRA. 0 texto se limita? Discussão baseada em Gérard Genette e [...]
P. $171-182$ 
35. RIO. $A$ alma encantadora das ruas, p. 32 .

36. RIO. $A$ alma encantadora das ruas, p. 32.

37. RIO. $A$ alma encantadora das ruas, p. 33.

38. RIO. $A$ alma encantadora das ruas, p. 33 .

39. RIO. $A$ alma encantadora das ruas, p. 33.
Não detalharemos, no presente trabalho, a definição apresentada por Joao do Rio para flânerie. Mais relevante, aqui, é destacar que o autor remete um elogio ambíguo ao flâneur. Por um lado, "flanar é a distinção de perambular com inteligência Nada como o inútil para ser artístico"35. O flâneur é "o bonhom me possuidor de uma alma igualitária e risonha, falando aos notáveis e aos humildes com doçura, porque de ambos conhece a face misteriosa" ${ }^{36}$. Consegue ver "o que os outros quase não podem entrever" ${ }^{\prime 7}$.Por outro lado, questiona-se, por meio de uma evocação direta ao leitor, o valor das "descobertas" feitas pelo flâneur: "Quando o flâneur deduz, ei-lo a concluir uma lei magnífica por ser para seu uso exclusivo (...). E é então que haveis de pasmar da futilidade do mundo e da inconcebível futilidade dos pedestres da poesia de observação" ${ }^{38}$.

Curiosamente, várias leis de pretensa validade universa são enunciadas em "A rua" e nas crônicas. A perspectiva de A alma se propõe a ultrapassar as capacidades observatórias da flânerie. Essa hipótese é reforçada pelo fato de, em "A rua”, o enunciador afirmar, referindo-se ao flâneur: "Eu fui um pouco esse tipo complexo"39 - enfatizo a expressão "um pouco". Pode-se pensar que a flânerie foi adotada apenas parcialmente como método e perspectiva. Sendo assim, surgem dúvidas: em que medida ela foi praticada? A operação de flanar está presente em todas as crônicas, ainda que fundida a outras "perspectivas"? O livro dispensa alguns atributos da flânerie? Quais as outras perspectivas que "tecem" os textos? Aqui não nos interessa apontar respostas a tais questões, mas apenas mostrar que estas enfraquecem a possibilidade de a declarada adoção da flânerie ser considerada um fator de unidade do livro.

Os efeitos da função prefacial de "A rua”, portanto, são dúbios. Por um lado, busca-se indicar a unidade temática e "perspectiva" do livro, mas, por outro, gera-se uma indeterminação sobre suas noções básicas (rua, alma da rua) e, também, em torno do que seria um de seus "métodos" (a (lânerie) $)^{40}$. Genette pontua:

Um tema de valorização própria, por uma razão evidente, dos prefácios de coletâneas (de poemas, de novelas, de ensaios) consiste em mostrar a unidade, formal ou na maioria das vezes temática, daquilo que corre o risco a priori de aparecer como um amontoado artificial e contingente. ${ }^{41}$

Esse tema ("mostrar a unidade") se exibe enfraquecido em "A rua”. O ensaio não parece propor qualquer justificativa que pretenda "demonstrar" a unidade do livro. Não parece buscar oferecer razões inequívocas para que esse conjunto específico de crônicas tenha sido reunido em um único livro. Em outras palavras, não intenta apresentar motivos para considerar-se a existência de uma totalidade coerente. No
40. A imprecisão "conceitual" se manifesta, por exemplo, na aparente falta de qualquer explicação "coerente" para o fato de as crônicas tratarem quase somente de espaços "ocupados" por personagens pobres, e para o fato de alguns desses espaços não serem públicos, mas sim de propriedade privada (por exemplo, casas para consumo de ópio na crônica "Visões d'ópio" e hospedarias miseráveis em "Sono calmo"). Tais espaços, aos quais apenas seus donos podem estatuto " "rua"? Na últim sec̃ão do livro "Onde às vezes termina a rua", há seis textos ambientados em presídios - esses espacos são o "término", no sentido de "extremidade", ou estão para além da rua? Continuidade ou interrupção?

41. GENETTE. Paratextos editoriais, p. 179.
EM TESE
BELO HORIZONTE
v. 22
N. 3
SET.-DEZ. 2016
VIEIRA. 0 texto se limita? Discussão baseada em Gérard Genette e [...]
P. $171-182$ 
42. Genette ressalta que "quem diz obra diz unidade e acabamento GENETTE. Paratextos editoriais, p. 183). Não é nesse sentido, no presente trabalho, que se empregam as palavras "livro" e "obra", categorias que, aqui, são questionadas.

43. A classificação do prefácio, por exemplo, em autentico, apocrifo ou fictício pode ser problematizada se se estuda um texto autoficcional. Neste caso, o prefácio atribuído a alguém homônimo do "autor real" seria qualificado como autêntico ou fictício? entanto, tampouco encontramos elementos para pensar-se que o livro se proponha justamente a agregar uma irredutível heterogeneidade de textos.

O ensaio "A rua", portanto, pode ter como efeito pôr em suspeição o pressuposto de que o livro tenha unidade - pressuposto que, segundo Melot, é inerente à forma-livro. A princípio, nada impede que uma leitura das crônicas subsequentes reduza, ao menos segundo a avaliação de determinado leitor, as indeterminações geradas por tal ensaio, mas intentamos demonstrar que elementos paratextuais podem funcionar como geradores de incertezas e, assim, contribuir para instabilizar e deslimitar a $o b r a^{42}$.

As classificações que Genette propõe para as funções da epígrafe e do prefácio, ainda que tais classificações admitam exceções (ver caso do prefácio de Caractères, no capítulo "A instância prefacial"), são excessivamente limitantes ${ }^{43}$. O mesmo julgamento se aplica à separação entre paratexto e texto, a qual reforça a ideia de ser este uma fortaleza. Mesmo a aparente licença que o teórico francês concede a uma noção menos enrijecida de obra não rompe os "muros" desta. Ao tratar de livros em que coexistem prefácios de diversas épocas e edições, Genette escreve:

Outros, como Scott ou Nodier, colocam no início o prefácio mais recente, como que exprimindo o estado presente de seu pensamento sobre a obra, e os anteriores em seguida, o que, ao mesmo tempo, os recua para o passado e os aproxima do texto até quase reabsorvê-los, ilustrando o princípio geral de que, com o tempo e perdendo sua função pragmática original, o paratexto, salvo desaparecimento, se "textualiza" e se integra à obra ${ }^{44}$.

O firme limite entre prefácio e texto poderia ceder - ou quase ceder - apenas quando o prefácio perdesse a função original - função, supostamente muito bem demarcada, de comentar o texto, não de confundir-se com este ${ }^{45}$.

Apesar das discordâncias já explicadas em relação a ideias de Genette, cabe ressaltar, à guisa de conclusão, o fato de o teórico sublinhar a importância, em qualquer livro, dos lugares em que seus elementos são posicionados. No seguinte trecho, Genette parece, indiretamente, lamentar que essa questão ganhe menos atenção do que merece. Após discutir os lugares em que diversos prefácios são impressos em edições eruditas, ele escreve:

Insistir aqui nesses detalhes filológicos pode parecer um rigor mas o crescente sucesso das edições eruditas e das coleções integrais justifica que nos preocupemos com seus efeitos de leitura, e a experiência prova que esses efeitos são largamente influenciados pela escolha de local ${ }^{46}$
44. GENETTE. Paratextos editoriais, p. 158.

45. Parece haver, no mesmo excerto ques estamos comentando, a defesa de uma autoridade de "textualizar" apo poderia se mais representasse quando năo do autor, ou quando, em outras palavras, o autor deixasse claro que o prefácio não mais exerce sua "função original". A presença, em Paratextos editoriais, da proposição da autoridade autor proposição da autoridade aut trabalhos futuros.

6. GENETTE Paratextos editoriais, p. 158. 
47. GENETTE. Paratextos editoriais, p. 176.

48. MELOT. Livro, p. 45.
No estudo de $A$ alma, por exemplo, sentimo-nos tentados a considerar o fato de "A rua" ser o primeiro texto da coletânea como sinal de sua função prefacial - "sua localização preliminar e, portanto, monitória”, aponta Genette ${ }^{47}$. Melot escreve: "A configuração que o livro confere ao texto já decidiu seu percurso. Seu início acaba sendo sua origem"48. A caracterização feita por Melot para a "dobra" mostra que os poderes desta, apesar de poderem ser perturbados, não devem ser subestimados.

\section{REFERÊNCIAS}

FOUCAULT, Michel. A arqueologia do saber. Tradução de Luiz Felipe Baeta Neves. Rio de Janeiro: Forense Universitária, 2008.

GENETTE, Gérard. Paratextos editoriais. Tradução de Álvaro Faleiros. Cotia: Ateliê Editorial, 2009

JEROME, Jerome K. 14 books in 1. S.I.: Shoes \& Ships \& Sealing Wax, 2006.

MELOT, Michel. Livro. Tradução de Marisa Midori Daeto e Valéria Guimarães. Cotia: Ateliê Editorial, 2012.

RIO, João do. A alma encantadora das ruas. São Paulo: Companhia das Letras, 2008 